\title{
Case Study Regarding the Role Of Physical Therapy in the Recovery of Column Deficit in J unior Tennis Players
}

\author{
Hodorcă Raluca Mihaela ${ }^{1 *}$ \\ Onose lonuţ ${ }^{2}$ \\ Ghițescu Alexandru ${ }^{3}$ \\ Albu Adriana 4 \\ Lucaci Paul ${ }^{5}$ \\ 1, 2, 3,5 "Al.I.Cuza" University of Iasi, 3, Toma Cozma, Romania \\ ${ }^{4}$ Gr. T. Popa" University of Medicine and Pharmacy of Iasi, 16, University, Romania
}

Keywords: field tennis, physical therapy, scoliosis

\begin{abstract}
Tennis has become increasingly popular in recent years but the coaches, focuses on the technique and tactic in the game and less on the issues they involve playing tennis, namely unilateral increase muscle tone which leads to the appearance of scoliotic attitudes. Hypothesis: using specific means of selected, we will improve posture junior tennis players with scoliotic attitude of the spine. Material and method: the study was conducted on a junior tennis player, age11, which participated in the sessions of physical therapy with a frequency of 2-3 times per week. Results and discussion: the patient E.S. was diagnosed with "C" shaped scoliosis. Using the scoliometer we obtained from initial testing a value of $7^{\circ}$ and the final value of only $4^{\circ}$. Conclusions: as a result of tests conducted confirmed the hypothesis that it was gone and that therapeutic exercise is imperative necessary to tennis players.
\end{abstract}

\section{Introduction}

Field tennis has become increasingly popular in recent years, a key factor in being raising the game. The number of practitioners is constantly increasing, the ratio of forces was balanced and motivation has become increasingly larger, mainly due to the prizes offered (Nicu, 2006).

In the foreground there is no normal physiological curve. Any deviation in the foreground is pathological, being either a functional scoliosis, either a structural one (Docu - Axelerad, 2009).

Therapeutic physical exercise is considered a fundamental action in physical therapy, which improves the situation of morpho-functional musculoskeletal segments, maintaining cardiovascular fitness and lead to physical and mental

\footnotetext{
*E-mail: raluca.hodorca@yahoo.com;
} 
recovery supporting the health of the patient (Marcu, 1999).

Physical therapy school in Boston (Sullivan, Markos, Minor) considers that a physical therapeutic exercise has three parts: "activity" (start position and what movements are being promoted in this posture), "technique" (kinetic techniques what are promoted) and "the elements" (actions that can contribute to an adjacent support intended purpose) (Ancuta, 2010).

The backbone makes us people and a few other animal species from other species, numerous but less dominant. The backbone confer body symmetry and direction of movement. It surrounds and protects our systems of communication and makes it possible to both mobility and stability, due to the overlapping of several pieces of bone coming from tube original cartilage. Thus, assures us the chance to take over and to dominate both the earth and the sky.

In physical therapy, how the physiotherapist operate is based on functional diagnosis, obtained by clinical diagnosis (put by the doctor) with the results of the initial evaluation (designed by the physical therapist).

There are difficulties in assessing and treating scoliosis, because no one can predict who will develop scoliosis progression rate of a curve.

\section{Material and methods}

Research hypothesis. We assume that by using specific selected means from physiotherapy, we will improve the posture of junior tennis players with abnormal spine curves.

The purpose of this paper is to develop a recovery program to assist in the recovery of the spine in the correct position in terms of anatomical, both of the spine and the patient's degree of training. (Being a professional tennis player, muscle tone is increased, the patient requires a specific recovery program: complex exercises, exercises with weights, volumes at a higher intensity).

The study was conducted on a single case, S.E., male, aged 11 years, diagnosed with scoliosis right curve what practice tennis for 6 years, 4-6 times a week. An important objective to ensure health and normalcy for children is the early detection of disabilities, so that they may not stabilize and create complications that may be difficult to correct. Among the tests used in the detection of scoliosis patient included in the study include: bullet wire test, frame analysis, Adam test (the inclination of the torso toward the previously), pain scale, electronic scoliometer.

Scoliometer is a specialized goniometry used to study the scoliotic column, namely for measuring angles of thoracic vertebral level hump and lumbar position, with the trunk inclined above (Cordun, 2009). Physical therapy has been applied during the period February to September 2016 with a frequency of 2-3 times a week and consisted of specific exercises, combined with specific elements of the game of tennis.

Have used strength exercises (exercises with dumbbells of varying sizes, elastic bands), the fixed ladder drills, drills, exercises with objects (balls, medical balls, stick, fizioball); also have used drills from corrective gymnastics (method 
Klapp and PNF) (Marcu, 2010), respiratory gymnastics and the abdominal exercises. It has put the emphasis on changing the length of the muscle: I followed through the drills used muscle shortening and lengthening shortened muscles, elongated to reach a muscle balance.

\section{Results and Discussions}

At the time of initial testing, the research record the following values: 149.5 $\mathrm{cm}$ high and $35.5 \mathrm{~kg}$. The results were calculated for the age of eleven. According to the data presented by Vasilov (1999), development topic is nonharmonic with less weight. La scala figures showed painful figure with the number 3 and visual scale of pain, the pain at level 5. At rest no longer felt pain, instead, felt pain ("something bothering") when they realize that certain movements or running certain exercises (for example, the position of the fixed scale, hung). The distance between the apex of the curvature and the bullet wire had a value equal to $7 \mathrm{~mm}$ and scoliometer has shown $7^{\circ}$ at thoracal level. (Table 1)

Table 1. Results obtained at the initial tests

\begin{tabular}{cc}
\hline Test & Results \\
\hline Height & $149,5 \mathrm{~cm}$ \\
Weight & $35,5 \mathrm{~kg}$ \\
Pain figure scala & 3 \\
Visual pain scala & 5 \\
Bullet Wire & $7 \mathrm{~mm}$ \\
Scolimeter & $7^{\circ}$ \\
\hline
\end{tabular}

As a result of the repetition of tests for the assessment of pain, the patient had an improvement. At scala's figures showed the figure with painful number 1 and the Visual scale of pain, the pain at level 2. At rest no longer felt pain, instead, felt pain ("something bothering") when they realize that certain movements or running certain exercises (for example, the position of the fixed scale, hung). The distance between the apex of the curvature of the plumb and dropped 3 millimetres. Scoliometer has shown $4^{\circ}$ thoracal level. (Table 2, Fig. 1)

Table 2. Results obtained at the final tests

\begin{tabular}{cc}
\hline Test & Results \\
\hline Height & $152 \mathrm{~cm}$ \\
Weight & $37 \mathrm{~kg}$ \\
Pain figure scala & 1 \\
Visual pain scala & 2 \\
Bullet Wire & $4 \mathrm{~mm}$ \\
Scolimeter & $4^{\circ}$ \\
\hline
\end{tabular}




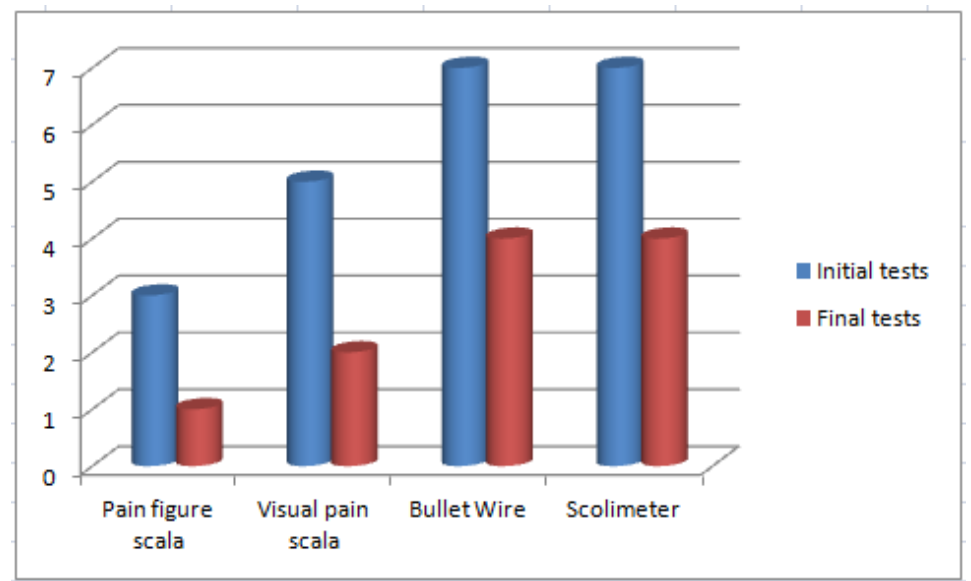

Figure 1. Comparison of the results

\section{Discussions}

Swärd (1992) reports that scoliosis is discovered in $80 \%$ of athletes with asymmetric loading of trunk and shoulders, such as javelin throwers and tennis players.

\section{Conclusions}

The results obtained from the study conducted concluded that tennis workouts are made in order to increase strength and unilateral ability which leads to a poor attitude of the spine, especially during periods of growth of children leads to pain and functional deficit. Making physical therapy in parallel with your workouts can stop the curb deficit evolution of the spine. Corrective physical drills practiced at disambiguation pages leading to optimal comfort at the level of the body, so in the summer period and beyond.

Of particular importance is maintaining the correct position to work at school and at home. In order to ensure the correct position it is recommended to work with table Ascension a inclinar desktop, to the school to force correct position.

Athletic activities and participation in sports are usually allowed to patients with scoliosis who use conservative methods of treatment, but caution is recommended in contact and highly dynamic sports activities (Jandric, 2015).

\section{References}

1. ANCUȚA, C. (2010). Esențialul în Medicină Fizică și Recuperare Medicală, Iași: Editura "Gr. T. Popa";

2. BALINT, T. (2007). Evaluarea aparatului locomotor, Iași: Editura Tehnopress;

3. CORDUN, M. (2009). Kinantropometrie, Bucureşti: Editura CD Press;

4. DOCU-AXELERAD, D. (2009). Kinetoterapia în scolioză, Constanța: Editura Fundației “Andrei Șaguna”; 
5. JANDRIC, S.D. (2015) Scoliosis and sport, SportLogia, Banja Luka, Bosnia and Herzegovina, 11(1): 1-10;

6. MARCU, V. (1999). Bazele teoretice și practice ale exercițiilor fizice în kinetoterapie, Oradea: Editura Universității;

7. MARCU, V. (2010). Manual de kinetoterapie, Oradea: Editura Universităţii din Oradea;

8. NICU, A. (2006). Istoria exercițiilor fizice, București: Editura Fundației "România de Mâine";

9. SWÄRD, L. (1992). The thoracolumbar spine in young elite athletes. Current concepts on the effects of physical training. Sports Med, 13(5): 357-364. doi: 10.2165/00007256-199213050- 00005

10. VASILOV, M. (1999). Dezvoltarea fizică a copiilor și tinerilor din județele Moldovei. Rezultatele anchetei medicale pe eșantion, Iași: Editura Fundației Altius Academi.

\title{
Studiu de Caz Privind Rolul Exercițiului Fizic în Recuperarea Atitudinilor Deficitare ale Coloanei la Tenismenii J uniori
}

\author{
Hodorcă Raluca Mihaela ${ }^{1}$ \\ Onose lonut ${ }^{2}$ \\ Ghițescu Alexandru ${ }^{3}$ \\ Albu Adriana 4 \\ Lucaci Paul ${ }^{5}$ \\ 1, 2, 3,5Universitatea "A. I. Cuza" din laşi, Str. Toma Cozma, 3, Romania \\ ${ }^{4}$ U. M.F. "Gr. T. Popa" Iasi,, Str. Universităţii, 16, Romania
}

Cuvinte cheie: tenis de câmp, kinetoterapie, scolioză

\section{Rezumat}

Tenisul de câmp a devenit din ce în ce mai cunoscut în ultimii ani iar antrenorii se focusează pe tehnică şi tactică în joc şi mai puțin problemele pe care le implica jocul de tenis şi anume creşterea tonusului muscular unilateral fapt ce duce la apariţia atitudinilor scoliotice. Ipoteză: prin folosirea mijloacelor selectate, specifice kinetoterapiei, vom îmbunătăți postura tenismenilor juniori cu deficiențe ale coloanei vertebrale. Material şi metodă: Studiul s-a realizat pe un tenismen în vârstă de 11 ani, diagnosticat cu ajutorul scoliometerului electronic, ce a participat la şedinţe de kinetoterapie cu o frecvență de 2-3 pe săptămână. Rezultate şi discuţii: Pacientul E.S. diagnosticat cu o scolioză în "C" dextroconvexă cu ajutorul scoliometerului a obţinut o ameliorare de $3^{\circ}$ între testări. Concluzii: În urma testărilor realizate s-a confirmat ipoteza de la care s-a plecat şi anume că exerciţiul fizic terapeutic este imperativ necesar la tenismenii de perfomanță. 


\section{Introducere}

Tenisul de câmp a devenit din ce în ce mai cunoscut în ultimii ani, un factor determinant fiind creșterea nivelului de joc. Numărul practicanților este în continuă creștere, raportul de forțe s-a echilibrat iar motivația a devenit din ce în ce mai mare, în principal datorită premiilor oferite.(Nicu, 2006)

În plan frontal nu există în mod normal curburi fiziologice. Orice deviaţie în plan frontal este patologică, fiind fie o scolioză funcţională, fie una structurală. (Docu-Axelerad, 2009).

Exercițiul fizic terapeutic este considerat $o$ acțiune fundamentală în kinetoterapie, ce îmbunătățește situația morfo-funcțională a segmentelor musculoscheletale, menține fitness-ul cardiovascular și conduce la recuperarea fizică și mentală susţinând starea de sănătate a pacientului. (Marcu, 1999)

Școala de kinetoterapie din Boston (Sullivan, Markos, Minor) consideră că un exercițiu fizic terapeutic are trei părți: "activitatea" (poziția de start și mișcările ce sunt promovate din această postură), "tehnica" (tehnicile kinetice ce sunt promovate) și "elementele" (acțiunile adiacente ce pot contribui la susținerea scopului propus). (Ancuta, 2010)

Coloana vertebrală ne diferențiază pe noi oamenii și încă alte câteva specii animale de celelalte specii numeroase, dar mai puțin dominante. Coloana vertebrală ne conferă simetria corpului și direcția de mișcare. Ea înconjură și protejează sistemele noastre de comunicare și face posibilă atât mobilitatea, cât și stabilitatea noastră, datorită suprapunerii a mai multor piese osoase provenite din tubul cartilaginos original.

În kinetoterapie, modul în care kinetoterapeutul își desfăşoară activitatea se bazează pe diagnosticul funcțional, obținut prin sumarea diagnosticului clinic (pus de către medicul specialist) cu rezultatele evaluării kinetice inițiale (realizată de către kinetoterapeut).

Există dificultăţi în evaluarea și tratarea scoliozei, deoarece nu se poate prevedea cine va dezvolta scolioza sau rata de progresie a unei curburi.

\section{Material şi metode}

Ipoteza cercetării. Presupunem că prin folosirea mijloacelor selectate, specifice kinetoterapiei, vom îmbunătăți postura tenismenilor juniori cu deficiențe ale coloanei vertebrale.

Scopul acestei lucrări este de a realiza un program de recuperare care să ajute la redresarea coloanei vertebrale în poziția corectă din punct de vedere anatomic, ținându-se cont atât de atitudinea coloanei vertebrale cât și de gradul de antrenament al pacientului. (Fiind sportiv, tonusul muscular este crescut, pacientul necesitând un program de recuperare specific: exerciţii complexe, exerciţii cu greutăţi, un volum și o intensitate mai mare).

Studiul s-a realizat pe un singur caz, pacientul S.E., de sex masculin, în vârstă de 11 ani, diagnosticat cu scolioză dextroconvexă ce practică sport de perfomanţă de 6 ani, de 4-6 ori pe săptămână. Un obiectiv important pentru asigurarea stării de sănătate și de normalitate a copiilor este reprezentat de depistarea precoce a 
deficiențelor, pentru ca ele să nu se stabilizeze și să creeze complicații care pot fi greu de corectat.

Printre testele utilizate în depistarea scoliozei pacientului cuprins în studiu se numără: testul firului cu plumb, analiza la cadrul somatoscopic, testul Adam (înclinarea trunchiului spre anterior - observarea gibozităţii), scara durerii, scoliometrul electronic. Scoliometerul este un goniometru specializat utilizat pentru studiul coloanei scoliotice, mai precis pentru măsurarea unghiurilor gibozităţilor vertebrale la nivel toracic şi lombar din pozitia stând cu trunchiul înclinat anterior (Cordun, 2009).

Kinetoterapia s-a aplicat în perioada februarie-septembrie 2016 cu o frecvenţă de 2-3 ori pe săptămână şi a constat în exerciții specifice kinetoterapiei, combinate cu elemente specifice jocului de tenis. S-au folosit exerciții cu rezistență (exerciţii cu gantere de diferite mărimi, benzi elastice), exerciţii la scara fixă, exerciții la banca de gimnastică, exerciții cu obiecte (mingi, mingi medicinale, baston, fizioball); de asemenea s-au folosit exerciții din gimnastica corectivă (metoda Klapp+FNP) (Marcu, 2010), din gimnastica respiratorie și din gimnastica abdominală.

S-a pus accentul pe modificarea lungimii musculaturii: prin exercițiile utilizate am urmărit alungirea musculaturii scurtate și scurtarea musculaturii alungite, pentru a ajunge la un echilibru muscular.

\section{Rezultate şi discuţii}

La momentul testării inițiale, subiectul cercetării înregistra următoarele valori: $149,5 \mathrm{~cm}$ înălțime și 35,5 kg. Rezultatele au fost calculate pentru vârsta de 11 ani. Conform datelor prezentate de către Vasilov (1999), dezvoltarea subiectului este dizarmonică cu minus de greutate. La scala figurilor dureroase a indicat figura cu numărul 3, iar pe scala vizuală a durerii, a situat durerea la nivelul 5. În repaus nu mai resimte dureri, în schimb, resimte dureri ("îl ține ceva") când realizează anumite mișcări sau execută anumite exerciții (de exemplu, în poziția atârnat, la scara fixă).

Distanța dintre apexul curburii și firul cu plumb a avut o valoare egala cu 7 $\mathrm{mm}$ iar scoliometer-ul a indicat $7^{\circ}$ la nivel toracal. (Tabel 1)

Tabel 1. Rezultatele obţinute la testările efectuate la începutul studiului

\begin{tabular}{cc}
\hline Testare & $\begin{array}{c}\text { Rezultate obținute la } \\
\text { testarea initiala }\end{array}$ \\
\hline Înălțime & $149,5 \mathrm{~cm}$ \\
Greutate & $35,5 \mathrm{~kg}$ \\
Scala figurilor dureroase & 3 \\
Scala vizuală a durerii & 5 \\
Testul firului cu plumb & \\
(distanța) & $7 \mathrm{~mm}$ \\
Scolimeter & $7^{\circ}$ \\
\hline
\end{tabular}


În urma repetării testelor de evaluare a durerii, pacientul a avut o îmbunătățire. La scala figurilor dureroase a indicat figura cu numărul 1, iar pe scala vizuală a durerii, a situat durerea la nivelul 2. În repaus nu mai resimte dureri, în schimb, resimte dureri ("îl ține ceva") când realizează anumite mișcări sau execută anumite exerciții (de exemplu, în poziția atârnat, la scara fixă). Distanța dintre apexul curburii și firul cu plumb a scăzut cu 3 milimetri. Scoliometer-ul a indicat $4^{\circ}$ la nivel toracal. (Tabel 2, Fig. 1)

Tabel 2. Rezultatele obţinute la testările efectuate la finalul studiului

\begin{tabular}{cc}
\hline Testare & $\begin{array}{c}\text { Rezultate obținute la } \\
\text { testarea finala }\end{array}$ \\
\hline Înălțime & $152 \mathrm{~cm}$ \\
Greutate & $37 \mathrm{~kg}$ \\
Scala figurilor dureroase & 1 \\
Scala vizuală a durerii & 2 \\
Testul firului cu plumb & \\
(distanța) & $4 \mathrm{~mm}$ \\
Scolimeter & $4^{\circ}$ \\
\hline
\end{tabular}

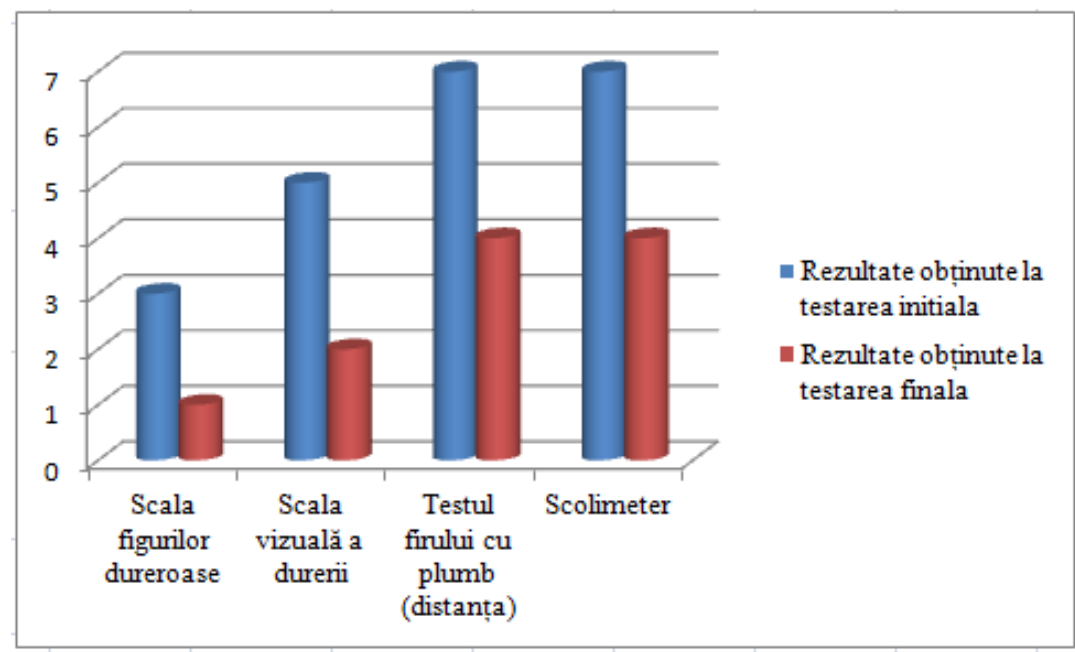

Figura 1. Rezultatele obţinute la testările efectuate

\section{Discuții}

Swärd (1992) afirmă că scolioza este apare în $80 \%$ din atleţii ce utilizează asimetric trunchiul şi umerii, cum ar fi aruncătorii de suliţă sau tenismenii. 


\section{Concluzii}

Rezultatele obţinute în urma studiului efectuat a concluzionat faptul că antrenamentele de tenis de câmp sunt realizate doar în vederea creştereii forţei şi îndemânării unilateral ceea ce duce la o atitudine deficitară a coloanei vertebrale, mai ales în perioadele de creştere ale copiilor provocând dureri şi deficit funcţional.

Efectuarea şedintelor de kinetoterapie în paralel cu antrenamentele pot stopa evoluţia deficitară a deviaţiei coloanei vertebrale. Exerciţiile fizice corective practicate la tenismeni duc la un confort optim la nivelul organismului, atât în perioada competițională, cât și în afara ei.

De o importanţă deosebită este menţinerea poziţiei corecte la masa de lucru de la şcoală şi de la domiciliu. Pentru a asigura o poziţie corectă se recomandă înălţarea mesei de lucru cu un pupitru inclinar, care să-l foţeze pe şcolar să adopte poziţia corectă.

Participarea la activităţile sportive sunt permise pacienţilor cu scolioză care utilizează metode conservative de tratament, dar se recomandă atenţie în privinţa activităţile dinamice. (Jandric, 2015) 